\title{
Testing reintroduction as a conservation strategy for the critically endangered Chinese alligator: Movements and home range of released captive individuals
}

\author{
WANG ZhengHuan ${ }^{1,2}$, YAO Hong ${ }^{1}$, DING YouZhong ${ }^{1,2}$, THORBJARNARSON John $^{3}$ \& \\ WANG XiaoMing ${ }^{1,2,4^{*}}$ \\ ${ }^{1}$ School of Life Sciences, East China Normal University, Shanghai 200062, China; \\ ${ }^{2}$ Shanghai Key Laboratory of Urbanization and Ecological Restoration, East China Normal University, Shanghai 200062, China; \\ ${ }^{3}$ Wildlife Conservation Society, 2300 Southern Boulevard, Bronx, New York 10460, USA; \\ ${ }^{4}$ Shanghai Science and Technology Museum, Shanghai 200171, China
}

Received May 4, 2011; accepted May 31, 2011

\begin{abstract}
The Chinese alligator (Alligator sinensis) is considered the most critically endangered crocodilian as a result of the near total loss of its habitat and its extremely small and fragmented wild populations. Plans for population recovery lie mostly with wetland restoration and the reintroduction of captive-reared animals. We carried out a first-trial release of 3 adult Chinese alligators (1 $0^{\star}, 2$ ) into a pond at the Hongxing conservation site, Xuancheng, southern Anhui Province; the animals were radio-tracked from May to October in 2003. We hypothesized that after a period of adaptation, the alligators would establish definable home ranges. Two $\left(10^{\lambda}, 1\right.$ q) of the 3 alligators were monitored for the whole of the tracking period. The male had an annual home-range size of 7.61 $\mathrm{hm}^{2}$, and the female $4.00 \mathrm{hm}^{2}$. Water temperature and pond water level were two important factors influencing the alligators' distributions, and daily movements. The radio-tracked alligators had overlapping home ranges, which notably included the one substantial island in the pond; that island is the only known nesting site of the local native wild alligators. Aggressive interactions between the released alligators and native wild alligators were observed during the breeding season around this island. All the three reintroduced alligators survived the winter of 2003 and were alive in the same pond in 2008. We concluded that the Hongxing conservation site provided a suitable habitat for the reintroduced alligators. However, the low water level in the pond resulting from farmland irrigation in August and September can be a substantial threat to the alligators' survival. Therefore, regulations on irrigation in summer and autumn are needed to balance the water needs of the alligators and agriculture.
\end{abstract}

Alligator sinensis, radio tracking, reintroduction, habitat, movement

Citation: Wang Z H, Yao H, Ding Y Z, et al. Testing reintroduction as a conservation strategy for the critically endangered Chinese alligator: Movements and home range of released captive individuals. Chinese Sci Bull, 2011, 56: 2586-2593, doi: 10.1007/s11434-011-4615-8

Habitat loss is an important factor leading to the global loss of biodiversity [1], and it is also the most important threat to wildlife in China [2]. The Chinese alligator (Alligator sinensis) is a good example of such a threat: this species is considered the most critically endangered crocodilian by the International Union for Conservation of Nature, principally as a result of habitat loss $[3,4]$.

*Corresponding author (email: xmwang@ecnu.edu.cn)
The Chinese alligator is a small crocodilian that historically was distributed over a large area in the middle and lower Changjiang (Yangtze) River basin in central-eastern China [5]. This region is one of the earliest areas for agriculture to develop, and the loss of lowland wetlands has been ongoing for a period of over 7000 years. By the 1950s, the Chinese alligator was extremely rare and was limited to a small area in southern Anhui and adjacent Zhejiang provinces [6]. Even this small distribution further decreased by some $75 \%$ between the 1950s and 1980s [7]. The Chinese 
alligator was listed as a Class I endangered species in China in 1972, and a 433- $\mathrm{km}^{2}$ nature reserve, the National Chinese Alligator Reserve (NCAR), and a breeding center, the Anhui Research Center for Chinese Alligator Reproduction (ARCCAR), were established in the mid-1980s. A large population of more than 7000 individuals is held in captivity at ARCCAR [8]. However, over the same period, the wild population size has decreased from 5000 to 6000 individuals in the 1950s $[9,10]$ to approximately 120 at the beginning of the 21 st century $[11,12]$. Presently, wild Chinese alligators can be observed only in 16 small, isolated conservation sites of the NCAR in southern Anhui and adjacent Zhejiang provinces, with a total area $<100 \mathrm{hm}^{2}$ [11]. The most recent field surveys have found alligators at only 14 conservation sites, and the largest subpopulation was 6 individuals living in a $3.37-\mathrm{hm}^{2}$ pond [12]. The highly fragmented nature of the wild population, the lack of any real habitat, and the tiny size of the wild population are 3 factors that predispose the species to becoming extinct in the wild unless conservation actions are taken.

Given the large number of captive-reared Chinese alligators, reintroduction of these animals has been actively under consideration as a conservation measure since 2000. Reintroduction of captive-reared individuals has been used as a technique to speed the population recovery of other endangered crocodilians, such as the Indian gharial [13] and Orinoco crocodile [14]. For Chinese alligators, the objective of reintroduction would be to augment the existing population of alligators in the NCAR as well as to establish new alligator populations in restored wetlands. Permanent water bodies (e.g., ponds and wetlands) in the alligators' habitat are critical to their survival [15], and the animals need to move between water and land to regulate their body temperature [16]. However, the remaining wild habitats in the NCAR are areas subject to intensive human agricultural use, principally rice cultivation. Periodic irrigation causes water levels in ponds and wetlands to change dramatically in different seasons, and this could be a threat to the survival of reintroduced alligators.

The first experimental release of Chinese alligators was conducted at the Hongxing conservation site in 2003. If captive alligators adapted successfully to wild habitats, they should: (1) survive and remain in the habitat of the release site; (2) establish definable home ranges after a period of adaptation. Therefore, to evaluate this adaptation, we reported the home range and movement of reintroduced Chinese alligators and evaluated the influence of environmental factors (i.e., temperatures and water levels) on the behavior of alligators.

\section{Materials and methods}

\subsection{Study area}

The study was carried out at the Hongxing conservation site $\left(30^{\circ} 46^{\prime} \mathrm{N}, 118^{\circ} 41^{\prime} \mathrm{E}\right)$, in Xuancheng, Anhui Province (Figure 1). The main body of water at Hongxing is a relatively small $\left(8 \mathrm{hm}^{2}\right)$ pond, which was created in 1958 by damming a small stream among low hills set in an intensively farmed landscape. Water in the pond is used mainly for irrigation and fish farming. The water depth ranges from $4.5 \mathrm{~m}$ in the north to $0.4 \mathrm{~m}$ in the south of the pond. There are two islands, one very small $\left(50 \mathrm{~m}^{2}\right)$ and a larger one (approximately $600 \mathrm{~m}^{2}$ ) that has been the traditional nesting site of alligators found in the pond prior to the release of captive animals. Recent surveys estimated 10 wild alligators in 1999 [11] and eight in 2003 [12]. Annual temperature extremes in Hongxing were $-14^{\circ} \mathrm{C}$ in January and $41.7^{\circ} \mathrm{C}$ in July; average annual precipitation was $1180 \mathrm{~mm}$ [17].

The land adjacent to the southern shore of the pond is used primarily for rice cultivation. The north shore is a dam, though secondary forest is the main land cover along the northeastern and northwestern shoreline. Principal species found in the forest include Robinia pseudoacacia, Cyclobalanopsis glauca, Castanopsis sclerophylla, Cunninghamia lanceolata, Pterocarya stenoptera, Sassafras tzumu, Quercus spp., and Phyllostachys heterocycla as the dominant canopy vegetation; Litsea coreana, Symplocos stellaris, Loropetalum chinense, Vaccinium bracteatum, Rosa multiflora and Pleioblastus amarus are the main shrub species.

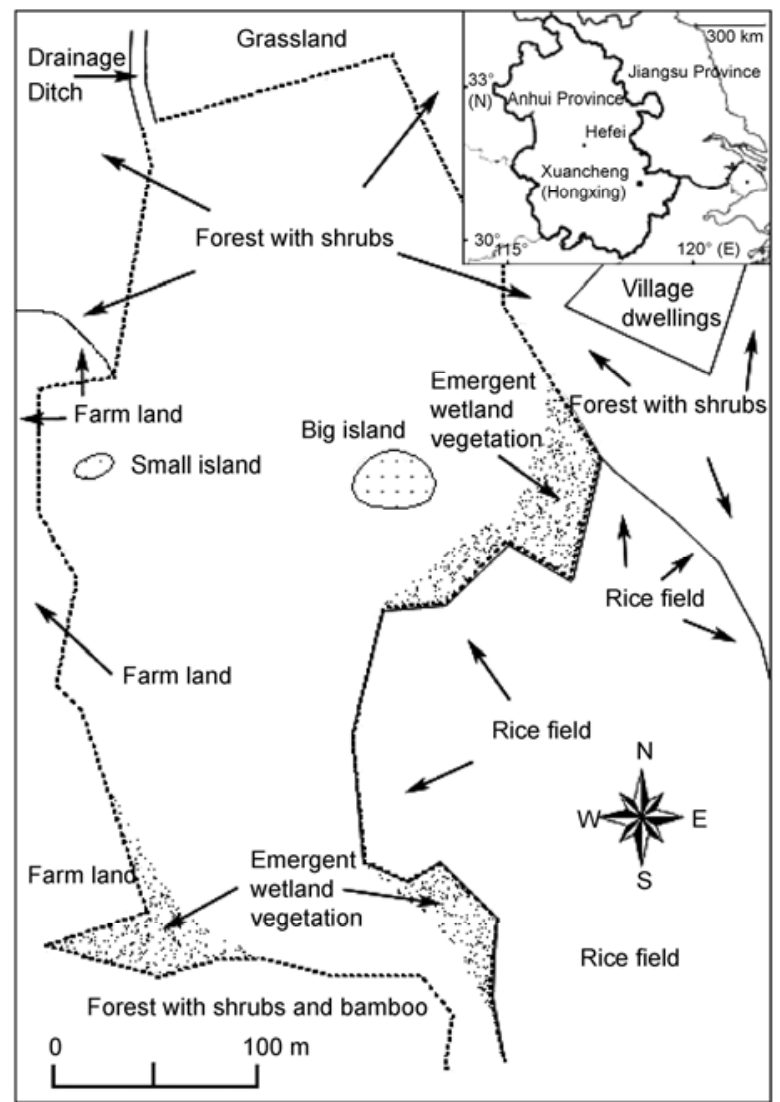

Figure 1 Map of the pond in the Hongxing Chinese alligator conservation site, Xuancheng. 
Emergent wetland vegetation, such as Phragmites communis, Typha orientalis, and Acorus calamus, is abundant along the eastern and southeastern edge, where the land along the shore is mainly used for growing rice (Figure 1).

\subsection{Alligator manipulation and telemetry}

We collected 13 adult Chinese alligators from ARCCAR. These individuals were checked for weight, body size, injury and disease. Finally, two females (504 fm and $584 \mathrm{fm}$ ) and one male $(528 \mathrm{~m})$ with the best physical condition were selected. Their identities, sexes, ages, body sizes, and weights are listed in Table 1. A radio transmitter (Advanced Telemetry Systems, Inc., Isanti, US) was attached to the dorsal surface of the tail of each alligator, and the animals were located using a TR-4 radio receiver with an A-14 H-type handheld antenna (Telonics, Inc., Mesa, US) in the field. Following release, the alligators were located every day at the following times: 06:00-08:00, 09:00-11:00, 12:00-14:00, 15:00-17:00, 18:00-20:00, and 22:00-24:00. Each time, we used a triangulation-based tracking protocol [18] to detect the position of the alligators from 3 observation stations with known coordinates. Locate III software (Pacer, Inc., Truro, Canada) was then used to calculate the coordinates of the alligators' positions. The mean error for the radio-tracking locations (triangulated vs. known locations) was $24.2 \pm 2.6 \mathrm{~m}( \pm \mathrm{SD}, n=11)$. The radio signal from $584 \mathrm{fm}$ was lost seven days later after release (Table 1). Therefore, we excluded that animal from further analysis of home-range and movement patterns. We were able to determine that the loss of signal was due to radio failure and that this female did survive and remain at Hongxing since it was sighted frequently during the radio-tracking seasons and the following year.

Each time we tracked the alligators, we measured the environmental temperature, including air and water temperatures. The air temperature was taken at a $1.5-\mathrm{m}$ height, and the water temperature was measured at a depth of $20 \mathrm{~cm}$ using a handheld thermometer in a shaded area at a fixed position on the eastern shore of the pond. We used four temperature variables in this study: daily minimum air temperature, daily maximum air temperature, daily minimum water temperature, and daily maximum water temperature. The water level was measured twice a day (06:00-08:00 and 18:00-20:00) by measuring the above water part length of a pole fixed in water. The longer the above water part of the pole was, the shallower the water level was.

\subsection{Data analysis}

To analyze annual patterns of ranging behavior, we divided the tracking period into three seasons [5]: spring (May to June), summer (July to August), and autumn (September to October). The home range and movement of the alligators and the influence of environmental factors were analyzed and compared in the different seasons.

(i) Home-range analysis. We calculated the home range and core area of the two alligators, $504 \mathrm{fm}$ and $528 \mathrm{~m}$, in the different seasons and for the whole tracking period. The core area is the area used most intensively by the animals in their home ranges. A 95\% minimum convex polygon (MCP) method was used to calculate the home range [18,19]. Evaluation of the core area in the home range indicated that each alligator had more than one core area (Figure 2), and MCP cannot be used in this situation [18]. Therefore, a 75\% fixed kernel estimator (FKE) [20] was used to calculate the core areas of the alligators. To control for autocorrelation among consecutive observations [21], one location per day for each alligator was used in the calculation. A pairedsample $t$-test was used to compare the home-range sizes of the two alligators in the different seasons. To test the influence of environmental factors on ranging behavior, we used the four temperature variables and water level to calculate their Spearman correlations with home ranges and core areas for each alligator in the three seasons.

(ii) Movement analysis. We estimated the minimum movement of alligators between two consecutive locations (the minimum movement of consecutive locations, hereafter MMCL) using the straight-line distance between the two points. A daily mean MMCL was then calculated by the sum of daily MMCLs divided by the number of MMCLs recorded that day. Data of the daily mean MMCL for each alligator in different seasons were compared to test the seasonal differences in movement by one-way analysis of variance. The $t$-test was used to compare the movement intensity of the male $(528 \mathrm{~m})$ and female $(504 \mathrm{fm})$ alligators based on the daily mean MMCL data for the entire radio-tracking period. The influences of water level and the four temperature variables on the alligators' movement were tested by calculating their Spearman correlations with

Table 1 Physical condition and telemetry details of the three Chinese alligators

\begin{tabular}{|c|c|c|c|c|c|c|c|}
\hline \multirow{2}{*}{ No. } & \multirow{2}{*}{ Sex } & \multirow{2}{*}{ Age (a) } & \multicolumn{4}{|c|}{ Body condition } & \multirow{2}{*}{$\begin{array}{c}\text { Tracking days } \\
\text { (valid number of locations) }\end{array}$} \\
\hline & & & Weight (kg) & Head length $(\mathrm{cm})$ & Snout vent length $(\mathrm{cm})$ & Total length $(\mathrm{cm})$ & \\
\hline $504 \mathrm{fm}$ & Female & 8 & 13.0 & 18.0 & 81.0 & 157.5 & $181(741)$ \\
\hline $528 \mathrm{~m}$ & Male & 8 & 17.0 & 19.9 & 84.0 & 168.0 & $156(755)$ \\
\hline $584 \mathrm{fm}$ & Female & 8 & 13.5 & 17.8 & 77.5 & 153.5 & $7(22)^{\mathrm{a})}$ \\
\hline
\end{tabular}

a) Signals from $584 \mathrm{fm}$ were lost $7 \mathrm{~d}$ after releasing. 

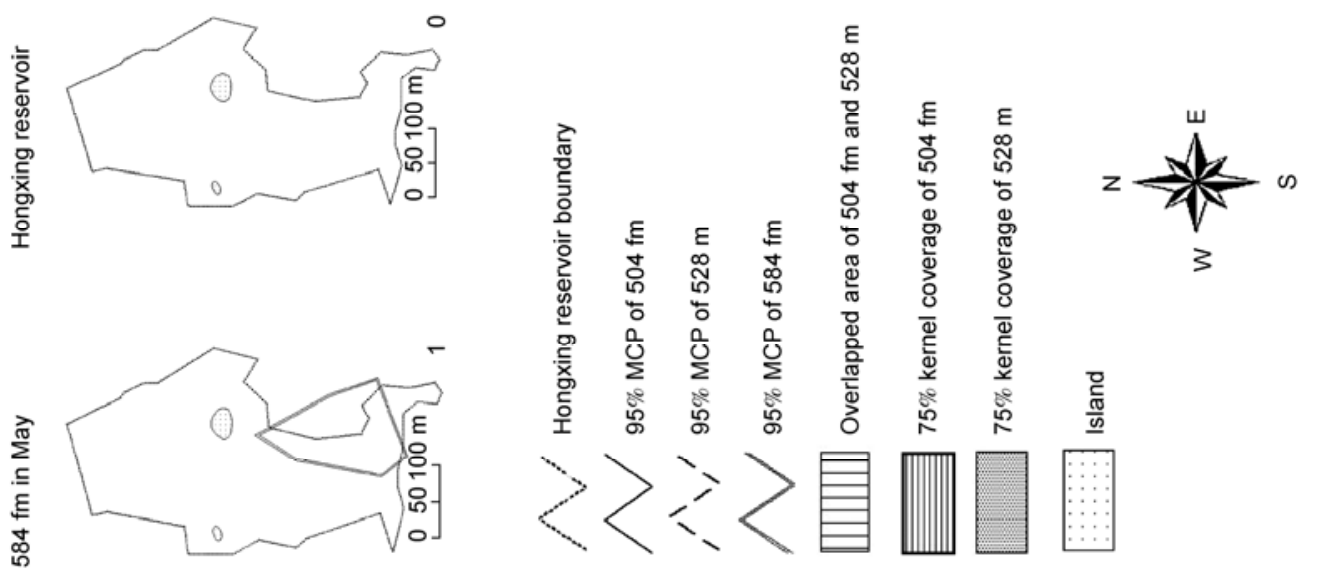

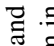

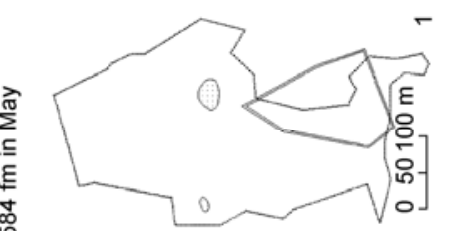

잉$$
\text { , }
$$
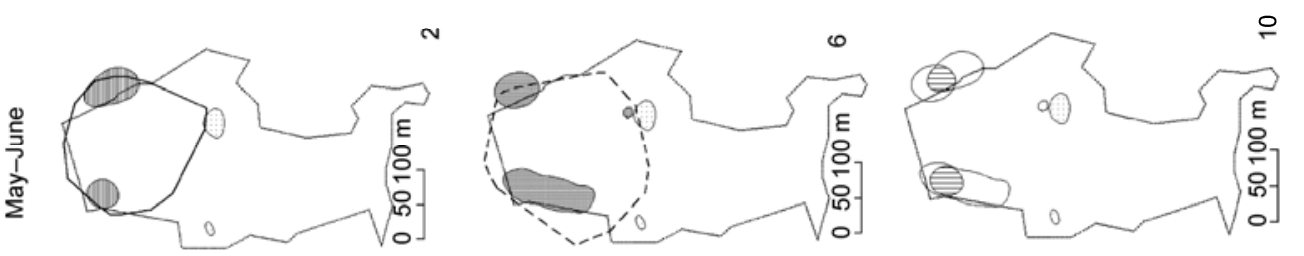

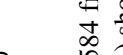
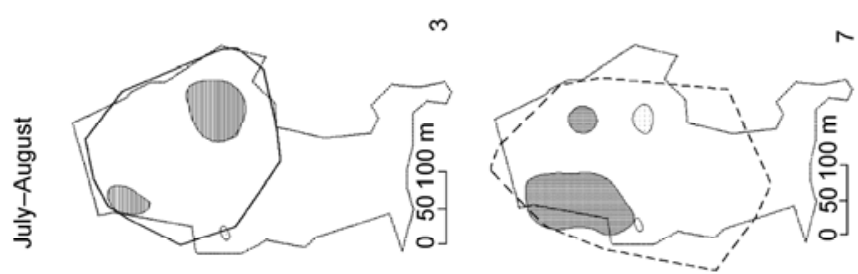
-

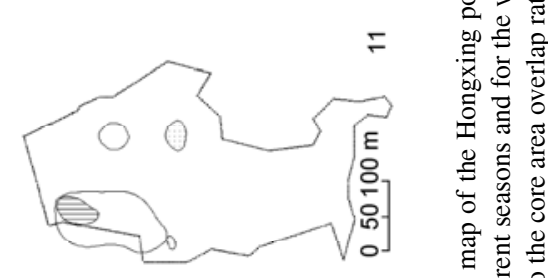

产要
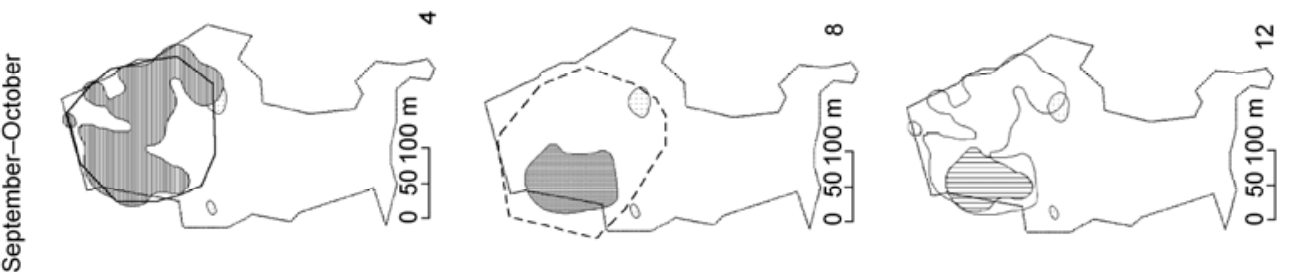

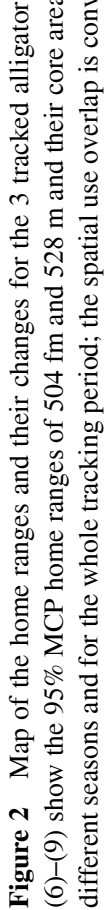
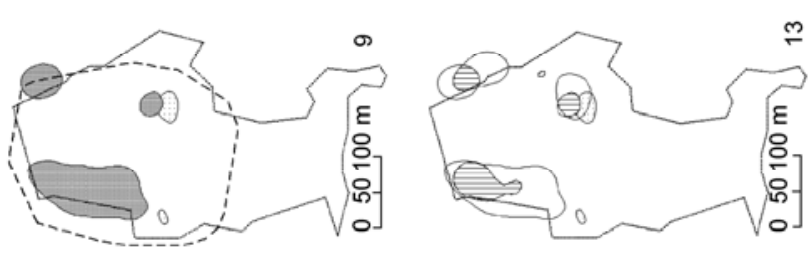

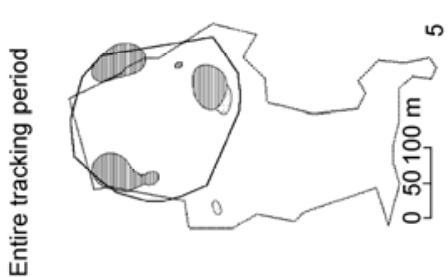

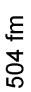

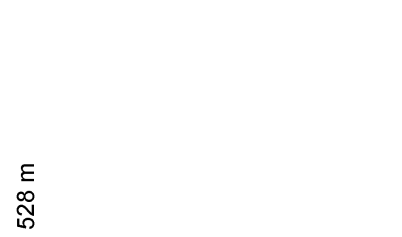

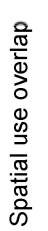

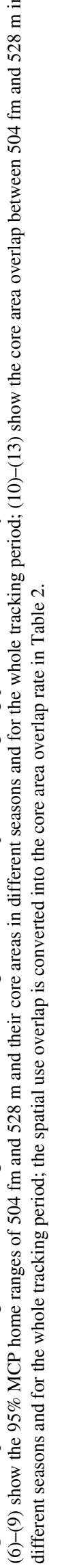


the daily mean MMCL for each animal. The MCP home range estimation was calculated using R2.6.2 (http://www. rproject.org/). All the spatial-distance and FKE calculations were carried out using Animal Movement Analysis 2.0 (USGS, Anchorage, US), which is a plug-in of ArcView 3.2a (ESRI, Inc., RedLands, US). Statistical tests were conducted using SPSS 15.0 (SPSS, Inc., Chicago, US).

\section{Results}

The 3 Chinese alligators were released at Hongxing on April 27, 2003. After 3 days' testing of the reliability of the radio-tracking stations and tracking protocol, regular field tracking began on May 1 and finished at the beginning of the hibernation period on October 27, 2003. We were able to track $504 \mathrm{fm}$ over a period of $181 \mathrm{~d}$ (741 valid locations) and $528 \mathrm{~m}$ over $156 \mathrm{~d}$ (755 locations) (Table 1). All the three alligators successfully overwintered and were observed again in 2004.

\subsection{Home range}

The $95 \%$ MCP estimation showed that $504 \mathrm{fm}$ had a total home range of $4.00 \mathrm{hm}^{2}$, and that of $528 \mathrm{~m}$ was $7.61 \mathrm{hm}^{2}$. We compared the areas of the two alligators' home ranges in each season. There were no significant differences at the 0.05 level $(t=-1.604, P=0.109)$. The two alligators had the greatest home range in summer (July and August); in the other two seasons, the home ranges shrank considerably
(Table 2, Figure 2). Both $504 \mathrm{fm}$ and $528 \mathrm{~m}$ mainly occupied the central and northern parts of the pond, while the one-week data for $584 \mathrm{fm}$ revealed that this female alligator was mainly located in the southeastern part of the pond, which is dominated by emergent wetland vegetation (Figures 1 and 2).

The core-area overlap was the lowest in summer; the highest overlap for $504 \mathrm{fm}$ was in spring and for $528 \mathrm{~m}$ in autumn (Figure 2, Table 2). Both alligators were frequently found in the northeastern and northwestern shore areas (Figure 2), where they were observed submerged in the water under overhanging vegetation or basking on shore. Both alligators frequented the main island during the tracking period. The female $(504 \mathrm{fm})$ showed stronger activity around the island from July to October (3 and 4 in Figure 2), although no nesting behavior was observed. The male (528 $\mathrm{m})$ was most frequently found near the island in May and June (6 in Figure 2).

Throughout the entire tracking period, the daily mean MMCL for $528 \mathrm{~m}(65.70 \pm 36.43 \mathrm{~m}, n=128)$ was significantly larger $(t=5.163, \mathrm{~d} f=269, P<0.001)$ than that for $504 \mathrm{fm}(43.80 \pm 33.39 \mathrm{~m}, n=143)$. The female $(504 \mathrm{fm})$ moved significantly less in spring than in either summer or autumn $(F=5.740, P=0.05)$, while the seasonal difference in movement of $528 \mathrm{~m}$ was not significant among all the three seasons $(F=0.907, P=0.409)$ (Table 3$)$.

\subsection{Influence of temperature and water level}

Temperatures were highest in summer, when both the daily

Table 2 Home ranges and core areas of $504 \mathrm{fm}$ and $528 \mathrm{~m}$ during the whole tracking period and in different seasons in 2003

\begin{tabular}{|c|c|c|c|c|c|}
\hline & & Entire tracking period & Spring (May to June) & Summer (July to August) & Autumn (September to October) \\
\hline \multirow{2}{*}{ Home ranges $\left(\mathrm{hm}^{2}\right)^{\mathrm{a})}$} & $504 \mathrm{fm}$ & 4.00 & 2.81 & 4.77 & 3.09 \\
\hline & $528 \mathrm{~m}$ & 7.61 & 3.77 & 7.61 & 3.80 \\
\hline \multirow{3}{*}{$\begin{array}{l}\text { Core areas }\left(\mathrm{hm}^{2}\right) \\
(\text { overlap rate })^{\mathrm{b})}\end{array}$} & $504 \mathrm{fm}$ & $0.7973(57 \%)$ & $0.4318(56 \%)$ & $0.6687(23 \%)$ & $2.2371(30 \%)$ \\
\hline & $528 \mathrm{~m}$ & $1.2229(37 \%)$ & $0.7147(34 \%)$ & $1.1447(14 \%)$ & $0.9354(72 \%)$ \\
\hline & Overlapped area & 0.4571 & 0.2434 & 0.1581 & 0.6781 \\
\hline
\end{tabular}

a) Calculated by the $95 \%$ MCP. b) Core areas were calculated by the $75 \%$ FKE, and the overlap rate was expressed by the overlapped core area between $504 \mathrm{fm}$ and $528 \mathrm{~m}$ divided by the core area of each alligator.

Table 3 Comparison of movements of $504 \mathrm{fm}$ and $528 \mathrm{~m}$ during the whole radio tracking period in $2003^{\text {a) }}$

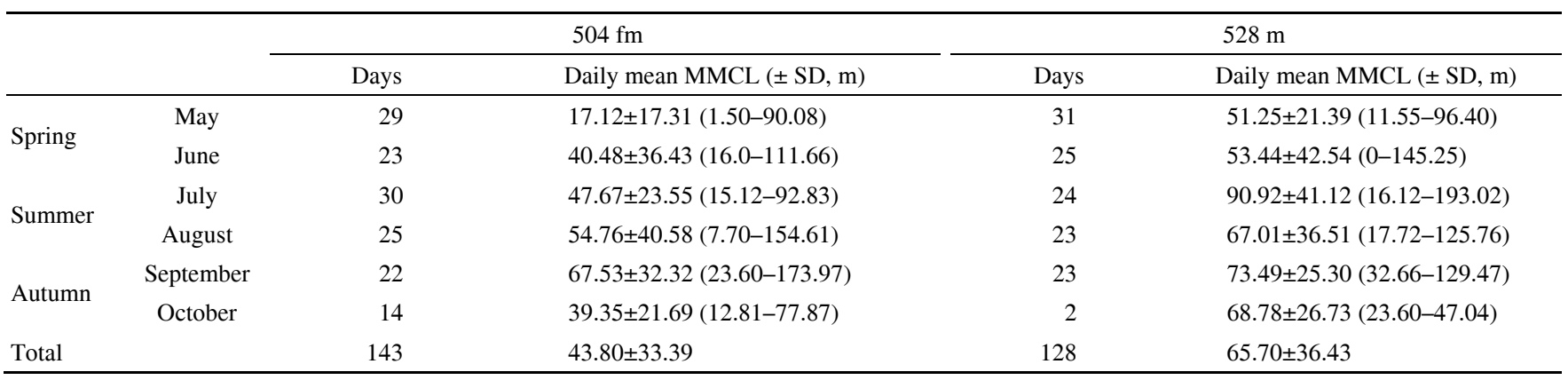

a) The MMCL means the minimum movement of alligators between the two consecutive locations calculated by the direct distance between the two time consecutive tracking locations. A daily mean MMCL was calculated by the sum of daily MMCLs divided by the number of MMCLs recorded that day. 
maximum air and water temperature could periodically reach $39^{\circ} \mathrm{C}$. The lowest temperatures were in autumn (i.e., October), with water temperatures dropping to $15^{\circ} \mathrm{C}$ and air temperatures to $3.5^{\circ} \mathrm{C}$ (Table 4). Temperature had a significant influence on the daily mean MMCL for both alligators (Table 5). For example, the daily maximum water temperature showed significant positive correlations with the daily mean MMCL for $504 \mathrm{fm}(\rho=0.771, P=0.036)$ and $528 \mathrm{~m}$ ( $\rho=0.829, P=0.021)$. However, the 4 temperature variables had no significant influence on the home range and core area of the alligators (Table 5).

\subsection{Movement}

The water level of the pond changed dramatically throughout the tracking period (Table 4). The shortest above water length of the pole in May was $41.6 \pm 3.8 \mathrm{~cm}$. The water level decreased more than $13 \mathrm{~cm}$ in June (mean above water length of the pole, $54.9 \pm 11.6 \mathrm{~cm}$ ). The rainy season in July caused the water level to rise by more than $20 \mathrm{~cm}$ $(31.5 \pm 13.9 \mathrm{~cm})$ compared with the level in June; the July level was the highest during the entire tracking period. However, because of a lack of rain and farmland irrigation, the water level dropped more than $58 \mathrm{~cm}(89.8 \pm 9.2 \mathrm{~cm})$ in August; the level was its lowest, dropping $60 \mathrm{~cm}(92.4 \pm 10.1$ $\mathrm{cm}$ ), in September, compared with the level in July. Although the water level rose approximately $19 \mathrm{~cm}$ in October
$(73.2 \pm 26.5 \mathrm{~cm})$, it was still $30 \mathrm{~cm}$ lower than in May. The water level had no significant influence on the home range, core area, and daily mean MMCL of the alligators (Table 5).

\section{Discussion}

Understanding animal behavior has long been regarded as essential to grasping the mechanisms involved in the extinction of species and instituting conservational activities to protect endangered species [22-24]. Among various kinds of behavior, ranging behavior is more obviously related to the reintroduction of endangered species and their habituation in fragmented habitats [25]. Chinese alligators usually hibernate from late October to the following April, breed in May and June, and nest from July to September [5,17,26]. Their ranging behavior should therefore follow the needs and factors in different seasons, such as breeding, nesting, and temperature regulation.

Both $504 \mathrm{fm}$ and $528 \mathrm{~m}$ showed obviously definable and stable home ranges in this study (Table 2, Figure 2). The two alligators restricted their activity to the northern part of the pond (Figure 2). Our study revealed that Chinese alligators may have smaller home ranges than those of the American alligator (Alligator mississippiensis) [27]. This could have resulted from the restrictions of the Hongxing pond. However, the small size of the home range and the fact that

Table 4 Temperatures and water levels in different months and seasons

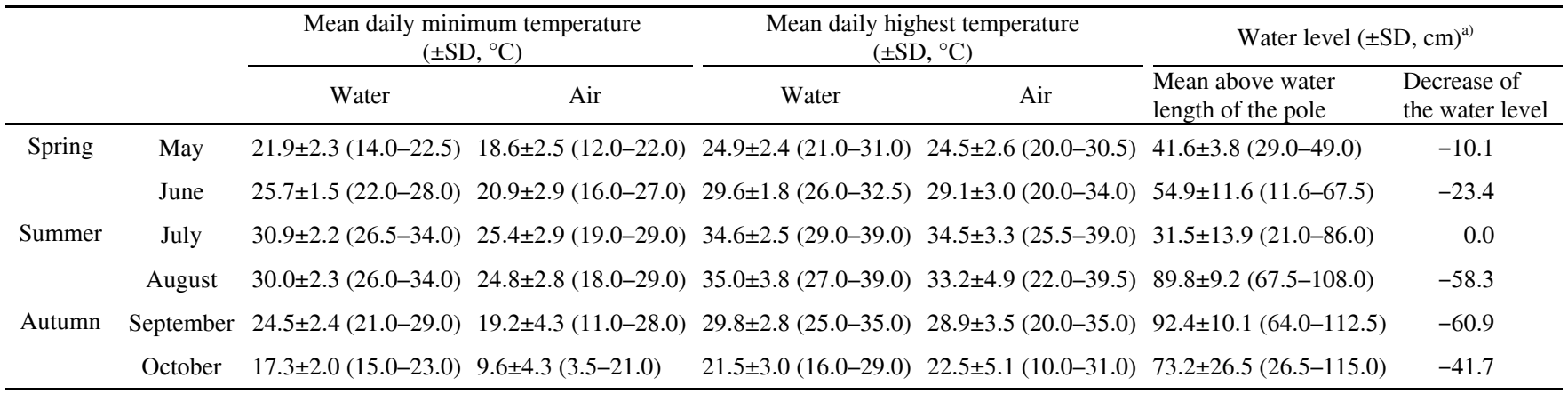

a) The water level of the pond was measured by the above water length of a pole fixed in the pond. The smaller the length, the deeper the water depth was. The decrease of the water level was calculated by the mean above water length of each month subtracting the mean above water length of July, when the deepest water depth was measured.

Table 5 Results of the Spearman correlation between environmental variables (temperature and water level) and ranging behavior of the tracked alligators

\begin{tabular}{|c|c|c|c|c|c|c|}
\hline & \multicolumn{3}{|c|}{$504 \mathrm{fm}$} & \multicolumn{3}{|c|}{$528 \mathrm{~m}$} \\
\hline & Home range & Core area & Daily mean MMCL & Home range & Core area & Daily mean MMCL \\
\hline Daily minimum air temperature & 0.598 & -0.239 & 0.714 & 0.598 & 0.598 & 0.600 \\
\hline Daily maximum air temperature & 0.598 & -0.239 & $0.829^{*}$ & 0.598 & 0.598 & 0.543 \\
\hline Daily minimum water temperature & 0.598 & -0.239 & $0.829^{*}$ & 0.598 & 0.598 & 0.543 \\
\hline Daily maximum water temperature & 0.717 & 0.000 & $0.829^{*}$ & 0.717 & 0.717 & $0.771^{\mathrm{a})}$ \\
\hline Water level & 0.120 & 0.598 & -0.029 & 0.120 & 0.120 & 0.600 \\
\hline
\end{tabular}

a) A significant Spearman correlation efficient with $P<0.05$. 
they remained at the release site proved that the Hongxiong conservation site can provide proper conditions for reintroduced alligators. Although the male alligator showed significantly stronger movement than the female (Table 4), this was not reflected in differences in sizes of their home ranges in different seasons.

A nearshore water area with a high density of tree and bush coverage is an important habitat in the survival of Chinese alligators. These animals' thermoregulation is highly reliant on behavior, especially regular movement between water and land [16]. There were three areas of high spatial utility for the two tracked alligators: the northeast and northwest shore areas, and the area around the big island (Figure 2). In these three areas, forest with shrubs was the main type of land cover (Figure 1), and little human activity was observed. The tracked alligators were frequently recorded submerged in water with overhanging trees and shrubs to avoid extreme high temperatures (e.g. $39^{\circ} \mathrm{C}$ in summer, Table 4) or basking on shore among shrubs in the three areas. In addition, vegetation-covered water can also provide alligators with good concealment, allowing them to avoid direct contact with adverse human activity.

The large southern part of the pond was little used by the two alligators. The shore area of the southern part of the pond was used mainly for agriculture, and disturbance caused by humans was common. Rice fields and other farmland extended to the edge of the pond, where there was no natural covering of shoreline vegetation, nor were there suitable sites for the alligators to bask out of the water [15]. This explains why the water-level variations did not influence the ranging behavior (i.e., home range and movement) significantly (Table 5). During the radio-tracking period, the water level in the pond decreased dramatically in late August and reached its lowest in September: the surface area of the pond was reduced by half. In September, the shallow area in the southern part of the pond was totally dry, but the deep northern part of the pond inhabited by the two tracked alligators was little affected. The home ranges of both tracked alligators were restricted to the deeper, northern part of the pond, which had less human disturbance (Figure 2). However, this restriction could have limited the alligators' foraging opportunities. Meanwhile, the water levels were so low that the water temperature in the pond reached dangerously high levels during the day (e.g., $39^{\circ} \mathrm{C}$ in August, Table 2). Alligators may avoid overheated surface water by retiring to deeper water $[16,28]$. Therefore, for an alligator habitat, a certain minimum water level has to be maintained throughout the spring to autumn activity period of the animals.

The territorial defense behavior has been studied widely in crocodilians. Some results showed that territorial defense was not important for the American alligator, Nile crocodile (Crocodilus niloticus), and estuarine crocodile (Crocodylus porosus) [27,30-32]. Likewise, we did not find any territo- rial defense behavior with the two tracked alligators. On the contrary, both alligators showed considerable overlap in their home ranges (Figure 2, Table 3). The only conflicts recorded were between the tracked alligators and wild alligators in the water around the big island from May to June, which is the alligators' breeding season. We observed a total of 11 conflicts: 3 with $504 \mathrm{fm}$, and 8 with $528 \mathrm{~m}$. The big island is the only known traditional nesting site for wild alligators in the Hongxing conservation site [17]; thus, it is important in breeding for the Hongxing alligator population. Conflicts typically occurred when the reintroduced alligators approached the big island. The wild alligators bit and chased the intruder. Each conflict ended up with the tracked alligators retreating from the big island, and the conflicts never lasted more than a minute. The conflicts imply that breeding and nesting sites may also be important factors in habitat selection for the tracked alligators. Although, we did not observe the tracked alligators breeding in 2003, a new nest on the big island in 2004 revealed that at least one female reintroduced alligator had started breeding (Wang and Thorbjarnarson, unpublished data, 2004).

Many studies have identified temperature as one of the main factors influencing crocodilians' ranging behavior, and the warmer season usually resulted in stronger movement and a larger home range [27-31,33]. Although temperature significantly influenced the movement of the two alligators, its influence on home-range variations of the two alligators in the three seasons was not significant (Table 5). This could be the result of the restriction in the available water area of the pond. Since the two alligators occupied only the northern part of the pond throughout the tracking period (Figure 2), the influence of temperature on the variation in home-range size was not obvious, although both alligators moved more when water temperature increased (Table 5).

Crocodilians in general are very adaptable animals. The radio-tracking project in 2003 proved that the tracked alligators did establish stable home ranges and remained in the pond where they were released. Including the female 584 $\mathrm{fm}$, all the three reintroduced alligators were found living in the pond in 2004, and one of the reintroduced females nested that year. A recent survey in Hongxing (May 2008) revealed that all the three alligators are still at the releasing site. Therefore, the reintroduction trial in 2003 should be considered successful. However, to improve alligator habitats, we suggest that two principal criteria be considered.

(i) Local communities in Hongxing have to balance irrigation practices with conservation of the Chinese alligator. A certain minimum water level of the pond needs to be maintained during the active period of the alligators.

(ii) To make better use of the southern part of the pond, buffer areas between farmland and the edge of the pond should be created. The natural shoreline covering vegetation should be restored in buffer areas to ensure that the alligators can conceal themselves, bask out of the water, and be 
separated from farming activities.

The staff from ARCCAR provided us with suitable alligators and necessary logistic support for this study. We appreciate the help of Dr. Bonnie Raphael of WCS for veterinarian support in selecting the alligators to be released and attaching the radio transmitters. Dr. Lu Qingbin and Mr. Li Xingqing helped us with the field tracking. We are grateful to Mr. Zhang Shixuan's family in the Hongxing conservation site for their kind support during the tracking work. This paper is in memory of Dr. John Thorbjarnarson and Mr. Zhang Shixuan. This work was technically and financially supported by the World Conservation Society (WCS).

1 Brooks T M, Mittermeier R A, Mittermeier C G, et al. Habitat loss and extinction in the hotspots of biodiversity. Conserv Biol, 2002, 16: 909-923

2 Biodiversity Committee of Chinese Academy of Science. Biodiversity in China: Status and Conservation Needs (in Chinese). Beijing: Science Press, 1992

3 Thorbjarnarson J, Wang X M. The conservation status of the Chinese alligator. Oryx, 1999, 33: 152-159

4 Wang S, Xie Y. China Species Red List (Vol. 1) (in Chinese). Beijing: Higher Education Press, 2004

5 Chen B H. Chinese Alligator (in Chinese). Hefei: Anhui Science and Technology Press, 1985

6 Huang C. The ecology of the Chinese alligator and changes in its geographical distribution. In: Crocodiles. Proceedings of the 5th Working Meeting of the IUCN/SSC Crocodile Specialist Group, Gland, 1982. 54-62

7 Huang Z J, Lin H Z, Zhang S K. An analysis of the remote sensing image of the Chinese alligator's habitat (in Chinese). Oceanol Limnol Sin, 1985, 16: 35-41

8 Wang W, Gu C M, Wang G S. Protection and management project of the existing wild population of Alligator sinensis in Anhui Province. In: Department of Wildlife Conservation State Forestry Administration, ed. Status Qui and Future of Conservation for Chinese Alligator and Crocodiles in the World. Beijing: China Forestry Publish House, 2002. 37-47

9 Zhu C G. Chinese alligator (in Chinese). Bull Biol, 1954, 9: 9-11

10 Zhu C G. Observations on the life history of Chinese alligator (Alligator sinensis) (in Chinese). Acta Zool Sin, 1957, 9: 129-143

11 Thorbjarnarson J, Wang X M, Shao M et al. Wild populations of the Chinese alligator approach extinction. Biol Conserv, 2002, 103: 93-102

12 Ding Y Z, Wang X M, Wang Z H, et al. Observation of activity in Chinese alligators released during an early period at Hongxing of Hanhui (in Chinese with English summary). Zool Res, 2004, 25: 27-31

13 Rao R J. Gharial re-introduction in Chambal River, India: A success story. Re-introduction News, 2006, 25: 16-17

14 Thorbjarnarson J, Wang X M. The Chinese Alligator. Baltimore: The Johns Hopkins University Press, 2010

15 Wang $\mathrm{H}$, Wang Z H, Wang Z W, et al. Study on behavioral thermoregulation of Chinese alligator under artificial feeding condition (in Chinese). Chinese J Zool, 2006, 41: 60-66

16 Muñoz M C, Thorbjarnarson J. Movement of captive-released Orinoco Crocodiles (Crocodylus intermedius) in the Capanaparo River, Venezuela. J Herpetol, 2000, 34: 397-403

17 Zhu H X. Observations on one wild population of Chinese alligator (in Chinese). Sichuan J Zool, 1997, 16: 129-143

18 White G C, Garrott R A. Analysis of Radio-tracking Data. San Diego: Academic Press, Inc., 1990

19 Row J R, Blouin-Demers G. Kernels are not accurate estimators of home-range size for Herpeto fauna. Copeia, 2006, 4: 797-802

20 Worton B J. Kernel methods for estimating the utilization distribution in home-range studies. Ecology, 1989, 70: 164-168

21 Swihart R K, Slade N A. Testing for independence of observations in animal movements. Ecology, 1985, 66: 1176-1184

22 Curio E. Conservation needs ethology. Trends Ecol Evol, 1996, 11: 260-263

23 Sutherland W J. The importance of behaviour in conservation biology. Anim Behav, 1998, 56: 801-810

24 Reed M J. The role of behaviour in recent avian extinctions and endangerments. Conserv Biol, 1999, 13: 232-241

25 Caro T. The behaviour-conservation interface. Trends Ecol Evol, 1999, 14: 366-369

26 He L J, Wang X M, Ding Y Z, et al. Influence of temperature on egg incubation of the wild Chinese alligator (Alligator sinensis) (in Chinese). Acta Zool Sin, 2002, 48: 420-424

27 Goodwin T M, Marion W R. Seasonal activity ranges and habitat preferences of adult alligators in a north-central Florida lake. J Herpetol, 1979, 13: 157-164

28 Smith E N. Behavioral and physiological thermoregulation of crocodilians. Am Zool, 1979, 19: 239-247

29 Chabreck R W. The movement of aliigators in Louisiana. Proc. Southeastern Game and Fish Commissioners Conference, 1965, 19: $102-110$

30 Hutton J. Movements, home range, dispersal and the separation of size classes in Nile crocodiles. Am Zool, 1989, 29: 1033-1049

31 Kay W R. Movements and home ranges of radio-tracked Crocodylus porosus in the Cambridge Gulf region of Western Australia. Wildlife Res, 2004, 31: 495-508

32 Joanen T, McNease L. A telemetric study of nesting female alligators on Rockefeller Refuge, Louisiana. Proc Southeastern Assoc Game and Fish Commissioners Conference, 1970, 24: 175-193

33 Joanen T, McNease L. A telemetric study of adult male alligators on Rockefeller Refuge, Louisiana. Proc Southeastern Assoc Game and Fish Commissioners Conference, 1972, 26: 252-275

Open Access This article is distributed under the terms of the Creative Commons Attribution License which permits any use, distribution, and reproduction in any medium, provided the original author(s) and source are credited. 